That is a sensible approach, but again one in which the opinions of the research community are likely to be represented by those of national government agencies. The two are not necessarily identical. Moreover, in the drive for coordination, there will inevitably be a risk that the value of research projects will be equated simply with the value, to industry or more broadly, of the knowledge they generate. But, as the whole world knows, research projects (especially in an academic setting) are the most effective way of generating the technical skill for which the modern world is crying out. Over-effective coordination could be the death of that.

That is one reason why the research community will be rightly suspicious of the commission's plans. Another is more practical: the commission has a poor track record in persuading the research community of the good sense of its decisions. That has much to do with the administrative muddle that often attends the award of research grants, but also with the sense that officials in Brussels have undue influence on the grants actually awarded even when these have been through a serious bout of peer-review (which process is not always serious). The practical goal, should be to conduct business in such a way as to persuade even those grant-seekers whom the commission must disappoint that their case has been considered fairly.

That, of course, is housekeeping and not strategy. What, beyond that, should the commission aim to do? One obvious need is to strengthen research in member states where it is at present neglected (Greece, Ireland and Portugal, for example). Doing that equitably will not be easy. Another is the pursuit of research in which the whole of Europe has an interest. With the emergence of bovine spongiform encephalopathy (BSE) as a disease of British cattle, and continued speculation about the risks to beef-eating people, should not the commission take an interest in prion diseases? Indeed, a competence in public health more generally would also be worthwhile. There is also a need for a mechanism for providing components of the research infrastructure intermediate in cost between projects such as those at CERN (the European Laboratory for Particle Physics) and those that national governments can conveniently provide. The station now established at Dwingeloo in the Netherlands for extracting meaningful data from very-long-baseline interferometric observations is only one of many examples.

In all these activities and others, the commission will succeed only if it can persuade the whole of Europe's research community of the good sense of its spending plans. But that will be more and not less difficult in the years immediately ahead. With the power struggle between the parliament and the council certain to intensify, the commission will be tempted to skimp on its more public role of carrying the community with it. That, after all, is how it has earned the reputation of being a dirigiste entity in other fields. The trouble, in research, is that the research community is likely to be even more resentful of what seems like top-down direction than are, say, European farmers. The commission would be wise to go carefully. Mme Cresson should, above all, be seen to be listening not just to ESTA but also to all the other bodies ready to offer her advice.

\section{Pitfalls of co-authorship}

\section{A disputed article in a British journal again reveals that co-authorship is not a free gift.}

THE British evidently have some way to go before they become sensitized to the improper use of the scientific literature. So much is clear from the circumstances surrounding the publication last August of a paper in the British Journal of Obstetrics and Gynaecology (101, 716-717; 1994) by J. M. Pearce, I. Manyonda and G. J. Chamberlain. The paper, in the journal's idiom a "case-report", described the transfer of an ectopic pregnancy to the uterus of the woman in whom its had developed; the paper claimed that the outcome was the successful birth of a child. Evidently the result would have been of some importance.

Doubts have been raised about the accuracy of the report on largely administrative grounds, notably that nobody at St George's Hospital in London can recall having assisted in the operation. The hospital has mounted an inquiry, as a consequence of which the first author of the paper, $\mathrm{Mr}$ Malcolm Pearce, has been suspended pending a decision on "what further action will be taken" by the hospital and the medical school associated with it. Pearce denies impropriety, and must be taken at his word while the findings of the hospital's inquiry remain secret (which is also proper while the hospital has not decided what further action, if any, to take).

But there is one issue that, even at this stage, will cause consternation in the research community. The third author is otherwise Sir Geoffrey Chamberlain, and happens to be both the current president of the Royal College of Obstetrics and Gynaecology and editor-in-chief of its journal, the British Journal of Obstetrics and Gynaecology. Pearce, on the other hand, is a member of Chamberlain's staff and one of several deputy editors of the same journal, which is published on behalf of the Royal College by Blackwell Scientific Press. Neither Chamberlain nor the third author, Dr I. Manyonda, is mentioned by the hospital as having been the subject of the inquiry carried out.

Indeed, Pearce is reported to have said that Chamberlain's name was included among the authors of the paper "purely as a courtesy, as head of the department". If true, that is an extraordinary statement, entirely at odds with the evidence that has accumulated elsewhere that 'honorary co-authorship' is a disreputable and also a dangerous practice. The fraudulent publications more than a decade ago attributable to John C. Darsee, first at Emory University and then at the Harvard Medical School, so sullied reputations at both institutions that honorary co-authorship is now widely regarded as a potentially poisoned chalice. It is also a misdemeanour in its own right, attributing credit where it does not belong. In the unfortunate case at St George's, it is important that the hospital should eventually say whether Chamberlain knew he had been cited as a co-author. The Royal College (which has set up an "independent" inquiry) should urgently take steps to rid its journal of insider publishing. 